\title{
TINGKAT KEKUMUHAN DAN ANALISIS SPASIAL PERMUKIMAN KUMUH PERKOTAAN (STUDI KASUS : SURABAYA TIMUR)
}

\author{
Anak Agung Sagung Alit Widyastuty ${ }^{1)}$, Jelita Citrawati Jihan ${ }^{2)}$ \\ ${ }^{1,2}$ Fakultas Teknik Sipil dan Perencanaan, Universitas PGRI Adi Buana \\ email: sagungalit@unipasby.ac.id
}

\begin{abstract}
Abstrak
Kota Surabaya yang dikenal sebagai kota yang berwawasan lingkungan ternyata masih memiliki 150 hektar kawasan permukiman yang masuk dalam kategori permukiman kumuh. Hal ini ditinjau dari kondisi sanitasi, ketersediaan drainase dan kondisi letak permukiman sekitarnya. Tujuan dari kajian ini adalah mengidentifikasi tingkat kekumuhan kawasan permukiman di Surabaya Timur serta menentukan arahan penanganannya. Rancangan penelitian yang digunakan adalah Deskriptif Kuantitatf dengan analisis skoring untuk menentukan tingkat kekumuhan dan analisis spasial untuk menentukan lokasi kawasan permukiman kumuh. Metode pengumpulan data dengan cara observasi dan wawancara serta studi literatur untuk mendapatkan data indikator tingkat kekumuhan di Kota Surabaya Timur. Tingkat kekumuhan permukiman di Surabaya Timur yang didapatkan dari hasil analisis adalah Permukiman di Kelurahan Sawunggaling dan Kelurahan Wonokusumo masuk dalam tingkat kekumuhan Sedang, sedangkan Kelurahan Kenjeran dan Kelurahan Rungkut Kidul termasuk dalam Tingkat Kekumuhan Tinggi. Analisis spasial yang dihasilkan dilihat dari keadaan dan status kondisi fisik permukiman adalah permukiman di kelurahan Sawunggaling dan kelurahan Wonokusumo termasuk dalam kategori kumuh sedang. Kelurahan Kenjeran dan kelurahan Rungkut Kidul termasuk dalam kategori kumuh berat.
\end{abstract}

Katakunci : Permukiman Kumuh, Kualitas Permukiman, Tingkat Kekumuhan.

\begin{abstract}
The city of Surabaya, which is known as an environmentally friendly city, still has 150 hectares of residential areas that fall into the category of slums. This is seen from the condition of sanitation, availability of drainage and the condition of the location of the surrounding settlements. The purpose of this study is to identify the level of slums of residential areas in East Surabaya and determine the direction for handling them. The research design used is descriptive quantitative with scoring analysis to determine the level of slums and spatial analysis to determine the location of slums. Methods of data collection by means of observation and interviews and literature studies to obtain data on indicators of slums in East Surabaya City. The level of settlement slums in East Surabaya obtained from the analysis was that settlements in Sawunggaling and Wonokusumo villages were included in the level of moderate slums, while Kenjeran and Rungkut Kidul villages were included in the high level of slums. The resulting spatial analysis based on the condition and status of the physical condition of the settlements are settlements in the Sawunggaling and Wonokusumo villages included in the category of medium slums. Kenjeran and Rungkut Kidul villages are in the category of heavy slums.
\end{abstract}

Keywords: Slum Settlements, Quality of Settlements, Level of Slums. 


\section{PENDAHULUAN}

Laju pertumbuhan penduduk yang pesat di daerah perkotaan membawa dampak beragam permasalahan seperti kemacetan dan kesemrawutan kota, kemiskinan, meningkatnya kriminalitas dan munculnya permukiman kumuh atau daerah slum (slum area), terutama di lahan - lahan kosong, seperti jalur hijau di sepanjang bantaran sungai, bantaran rel kereta api, taman - taman kota ataupun di bawah jalan layang (Jamaludin, 2015). Permukiman kumuh adalah permukiman yang padat, kualitas konstruksi rendah, prasarana dan pelayanan permukiman minim merupakan akibat dari kemiskinan (Kuswartojo, Rosnarti, Effendi, K, \& Sidi, 2005). Hampir semua kota di Negara berkembang menunjukkan adanya permukiman kumuh di bagian bagian kotanya. Indonesia merupakan negara berkembang yang terdiri dari kota-kota besar dan pemukiman kumuh merupakan masalah yang dihadapi oleh hampir semua kota - kota di lainnya, serta kawasan ini merupakan bagian yang terabaikan dalam pembangunan perkotaan. Pertumbuhan penduduk yang meningkat pesat dan pertambahan jumlah perumahan yang disediakan di kota tidak seimbang, sehingga menjadi menyebabkan tumbuhnya permukiman kumuh. Perkembangan ekonomi kota yang pesat menimbulkan adanya arus Urbanisasi. Keberadaan kaum urban diperkotaan seringkali tidak diimbangi dengan kemampuan skill yang memadahi untuk mendapatkan pekerjaan dan jumlah lapangan pekerjaan sangat terbatas. Sebagian besar kaum urban mengalami kegagalan dikarenakan kompetisi tersebut. sehingga tidak mampu membeli rumah yang layak, mereka terpaksa berada di tempat-tempat yang tidak layak.

$$
\text { Menurut Peraturan Menteri }
$$

Pekerjaan Umum dan Perumahan Rakyat No 2 tahun 2016, Pemukiman Kumuh adalah pemukiman yang tidak layak huni karena ketidakteraturan bangunan, tingkat kepadatan bangunan yang tinggi dan kualitas bangunan serta sarana prasarana yang tidak memenuhi syarat. Menurut UU No 1 tahun 2011, Kriteria kumuh sendiri terbagi menjadi bangunan gedung, jalan lingkungan, penyediaan air minum, drainase lingkungan, pengelolaan limbah, pengelolaan persampahan dam potensi bahaya kebakaran. Permukiman kumuh di Indonesia sendiri diprediksi akan terus meningkat setiap tahun (Yuliani \& D Rosyida, 2017).

Kota Surabaya sebagai salah satu kota besar ke - 2 di Indonesia mengalami fenomena permukiman kumuh. Dengan luas wilayah 274,06 Km2 yang dibagi dalam 31 kecamatan dan 163 kelurahan, julah penduduk kota Surabaya pada tahun 2012 mencapai 3.110.187 juta jiwa (Anoraga et al., 2014). Kota Surabaya yang dikenal sebagai kota berwawasan lingkungan, ternyata masih ada sekitar 150 hektar kawasan permukiman masuk dalam kategori kawasan permukiman kumuh (Zahro,2017). Berdasarkan kompleksitas gejalanya, permukiman kumuh illegal di Surabaya pusat, dapat ditinjau dari proses terbentuknya yakni merupakan gejala buatan manusia berupa bangunan rumah yang tidak layak huni dilahan yang bukan miliknya atau tidak mempunyai hak kepemilikan lahan (Kurniati A \& Suhardi, 2012). Tujuan dari penelitian ini adalah mengidentifikasi tingkat kekumuhan kawasan permukiman di Surabaya Timur serta menentukan arahan penanganannya. 


\section{METODOLOGI}

Rancangan Penelitian selama pelaksanaan adalah analisis Deskriptif kuantitatif dengan analisis skoring tingkat kekumuhan di kelurahan Sawunggaling, Kenjeran, Rungkut Kidul dan Wonokusumo wilayah studi Surabaya Timur yang dijabarkan dalam gambar 1.

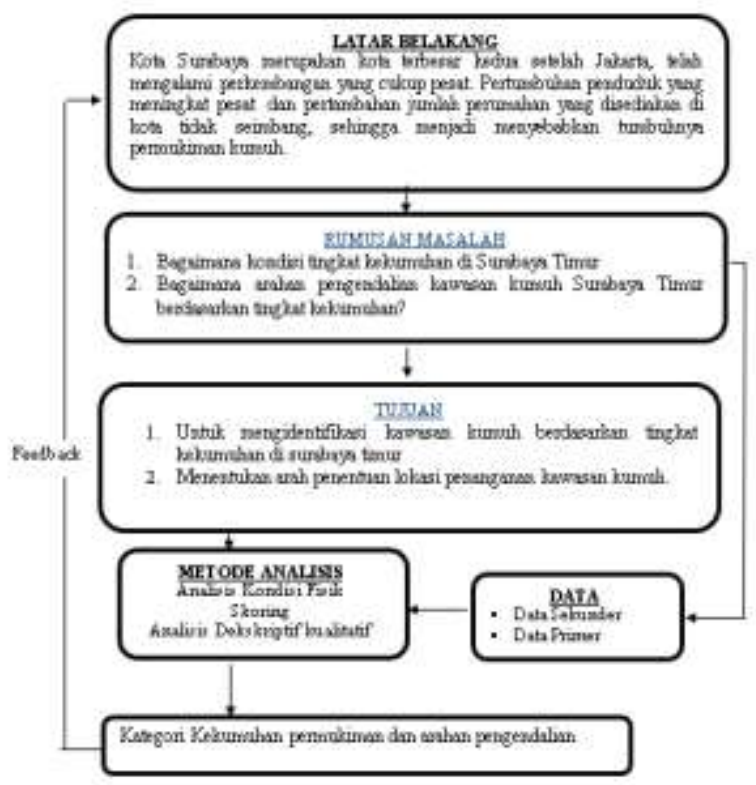

Gambar 1. Rancangan Penelitian

Variabel- variabel penelitian yang digunakan untuk mengkaji adalah berupa :

1. Aspek Kependudukan

2. Aspek Kondisi Fisik

3. Tingkat Kekumuhan Perkotaan

\section{Tahap Pengumpulan Data}

a. Data primer dikumpulkan melalui survai primer yang dilakukan melalui pengamatan dan pengukuran atau perhitungan langsung (observasi) di lapangan untuk mengetahui keadaan dan kondisi permukiman.

b. Sumber sekunder merupakan sumber data yang berasal dari instansi yang terkait dengan studi untuk mendapatkan data-data yang dibutuhkan untuk kegiatan analisis.

1) Data Demografi dan kondisi fisik dasar diperoleh dari Kantor Kelurahan wilayah penelitian
2) Kondisi sosial ekonomi masyarakat dari Kantor Kelurahan

\section{Metode Analisis}

Tingkat kekumuhan melalui analisis kuantitatif dengan menelaah standar, indikator tingkat kekumuhan dari Permen PUPRNo.2/PRT/M/2016 tentang Peningkatan Kualitas Perumahan dan Kawasan Permukiman. Penilaian lokasi permukiman kumuh berdasarkan kompleksitas permasalahan yang ada di lokasi permukiman kumuh yang telah teridentifikasi pada tahap sebelumnya (Pekerjaan Umum dan Perumahan Rakyat No. 2, 2016).

Penilaian lokasi dilakukan untuk menilai tingkat kekumuhan dari hasil identifikasi lokasi terhadap aspek:

a. Kumuh kategori tingkat ringan;

b. Kumuh kategori tingkat sedang; dan

c. Kumuh kategori tingkat berat.

Berdasarkan pra survey yang telah dilakukan, ditentukan ruang lingkup wilayah penelitian yang akan di nilai tingkat kekumuhannya, yaitu kelurahan Kenjeran, Kelurahan Rungkut Timur, Kelurahan Sawunggaling dan Kelurahan Wonokusumo yang kesemuanya berada di lingkup administrasi Surabaya Timur. Tahap finishing pengerjaan Kajian ini terdiri dari analisis spasial secara visual untuk memberikan gambaran kondisi dan komponen fisik kawasan kumuh. Kemudian, dibangun suatu sistem informasi geografis dengan menambahkan juga data atribut yang digunakan.

\section{HASIL DA N PEMBAHASAN}

1.Tingkat kekumuhan berdasarkan Tipologi Perumahan Kumuh dan Permukiman Kumuh

a. Fungsi dan Kegiatan

Pola kawasan permukiman kumuh yang ada di Kota Surabaya umumnya terbentuk mengelompok (concentric) kemudian mengalami 
Anak Agung Sagung Alit W. \& Jelita Citrawati Jihan : Tingkat Kekumuhan dan Analisis Spasial Permukiman Kumuh Perkotaan (Studi Kasus : Surabaya Timur)

perkembangan secara linier mengikuti jaringan jalan dan bersifat alami memiliki kegiatan yang heterogen. Sebagian besar penduduk memanfaatkan tempat tinggal untuk membuka usaha, fungsi dari permukiman kemudian mengalami perubahan menjadi campuran antara hunian dan tempat usaha.

Kegiatan di permukiman tersebut berbeda-beda antara lain warung makan, kios pulsa, jualan peracangan.

b. Bangunan
Kondisi bangunan/rumah sesuai hasil survey sebagian besar semi permanen, dan sebagian kecil temporer. Kondisi rumah dinding non permanen (kayu dan seng) di kelurahan Wonokusumo dan kelurahan Kenjeran. Kawasan kumuh di kelurahan Sawunggaling disebabkan oleh bangunan tidak layak huni. Kawasan kumuh di kelurahan Rungkut Kidul disebabkan oleh jarak antar bangunan yang berdekatan.

Tabel 1. Penilaian Lokasi Berdasarkan Kriteria, Indikator Dan Parameter Kekumuhan

\begin{tabular}{|c|c|c|c|c|c|c|c|c|}
\hline \multirow[t]{2}{*}{ No } & \multirow[t]{2}{*}{ Aspek } & \multirow[t]{2}{*}{ Kriteria } & \multirow[t]{2}{*}{ Indikator dan parameter } & \multirow[t]{2}{*}{ Nilai } & \multicolumn{4}{|c|}{ Lokasi permukiman kumuh } \\
\hline & & & & & Sawunggaling & Kenjeran & Rungkut Kidul & Wonokusumo \\
\hline A & Identifikasi Kondisi Kekumuhan (Fisik) & & & & & & & \\
\hline \multirow[t]{9}{*}{1} & \multirow[t]{9}{*}{ Kondisi Bangunan } & \multirow{3}{*}{$\begin{array}{l}\text { Ketidakteraturan } \\
\text { bangunan }\end{array}$} & $76 \%-100 \%$ (tidak teratur) & 5 & & 5 & 5 & \\
\hline & & & $51 \%-75 \%$ (tidak teratur) & 3 & 3 & & & 3 \\
\hline & & & $25 \%-50 \%$ (tidak Teratur) & 1 & & & & \\
\hline & & \multirow{3}{*}{$\begin{array}{l}\text { Tingkat } \\
\text { Kepadatan } \\
\text { Bangunan }\end{array}$} & $\begin{array}{l}76 \%-100 \% \text { (tidak sesuai } \\
\text { peraturan) }\end{array}$ & 5 & & 5 & 5 & \\
\hline & & & $\begin{array}{l}51 \%-75 \% \text { (tidak sesuai } \\
\text { peraturan) }\end{array}$ & 3 & 3 & & & 3 \\
\hline & & & $\begin{array}{l}25 \%-50 \% \text { (tidak sesuai } \\
\text { peraturan) }\end{array}$ & 1 & & & & \\
\hline & & \multirow{3}{*}{$\begin{array}{l}\text { Ketidaksesuaian } \\
\text { dengan } \\
\text { persyaratan letak } \\
\text { bangunan }\end{array}$} & $\begin{array}{l}76 \%-100 \% \text { (tidak sesuai } \\
\text { peraturan) }\end{array}$ & 5 & & 5 & 5 & \\
\hline & & & $\begin{array}{l}51 \%-75 \% \text { (tidak sesuai } \\
\text { peraturan) }\end{array}$ & 3 & 3 & & & 3 \\
\hline & & & $\begin{array}{l}25 \%-50 \% \text { (tidak sesuai } \\
\text { peraturan) }\end{array}$ & 1 & & & & \\
\hline \multirow[t]{6}{*}{2} & \multirow[t]{6}{*}{ Kondisi Jalan Lingkungan } & \multirow{3}{*}{$\begin{array}{l}\text { Cakupan } \\
\text { Pelayanan Jalan } \\
\text { Lingkungan }\end{array}$} & $\begin{array}{l}76 \%-100 \% \text { (tidak terlayani } \\
\text { jalan lingkungan) }\end{array}$ & 5 & & & & \\
\hline & & & $\begin{array}{l}51 \%-75 \% \text { (tidak terlayani jalan } \\
\text { lingkungan) }\end{array}$ & 3 & 3 & & & 3 \\
\hline & & & $\begin{array}{l}25 \%-50 \% \text { (tidak terlayani jalan } \\
\text { lingkungan) }\end{array}$ & 1 & & 1 & 1 & \\
\hline & & \multirow{3}{*}{$\begin{array}{l}\text { Kualitas } \\
\text { Permukiman } \\
\text { Jalan }\end{array}$} & $\begin{array}{l}76 \%-100 \% \text { (Kualitas Jalan } \\
\text { Buruk) }\end{array}$ & 5 & & & & \\
\hline & & & $\begin{array}{l}51 \%-75 \% \text { (Kualitas Jalan } \\
\text { Buruk) }\end{array}$ & 3 & & & & \\
\hline & & & $\begin{array}{l}25 \%-50 \% \text { (Kualitas Jalan } \\
\text { Buruk) }\end{array}$ & 1 & 1 & 1 & 1 & 1 \\
\hline 3 & Kondisi Penyediaan Air Bersih & & & & 8 & 10 & 6 & 6 \\
\hline 4 & Kondisi Drainase Lingkungan & & & & 13 & 15 & 23 & 11 \\
\hline 5 & Kondisi Pengelolaan Air Limbah & & & & 10 & 10 & 10 & 10 \\
\hline 6 & Kondisi Pengelolaan Persampahan & & & & 11 & 15 & 15 & 7 \\
\hline \multirow[t]{2}{*}{7} & Kondisi Proteksi Kebakaran & & & & 10 & 10 & 10 & 10 \\
\hline & & & Sub Total & & 65 & 77 & 81 & 57 \\
\hline$B$ & Identifikasi Pertimbangan Lain & & & & & & & \\
\hline \multirow[t]{7}{*}{8} & \multirow[t]{7}{*}{ Pertimbangan lain } & \multirow[t]{2}{*}{$\begin{array}{l}\text { Nilai strategis } \\
\text { lokasi }\end{array}$} & $\begin{array}{l}\text { Lokasi terletak pada fungsi } \\
\text { strategis kabupaten / kota }\end{array}$ & 5 & & 5 & 5 & \\
\hline & & & $\begin{array}{l}\text { Lokasi tidak terletak pada fungsi } \\
\text { strategis kabupaten / kota }\end{array}$ & 1 & 1 & & & 1 \\
\hline & & \multirow[t]{3}{*}{ Kependudukan } & $\begin{array}{l}\text { Kepadatan penduduk pada } \\
\text { lokasi sebesar }>200 \mathrm{jiwa} / \mathrm{ha}\end{array}$ & 5 & & 5 & 5 & \\
\hline & & & $\begin{array}{l}\text { Kepadatan penduduk pada } \\
\text { lokasi sebesar } 150-200 \text { jiwa / } \\
\text { ha }\end{array}$ & 3 & & & & \\
\hline & & & $\begin{array}{l}\text { Kepadatan penduduk pada } \\
\text { lokasi sebesar }<150 \text { jiwa / ha }\end{array}$ & 1 & 1 & & & 1 \\
\hline & & \multicolumn{2}{|c|}{ Kondisi sosial, ekonomi dan budaya } & & 1 & 1 & 1 & 1 \\
\hline & & & Sub Total & & 3 & 11 & 11 & 3 \\
\hline C & Identifikasi Legalitas Lahan & & & & & & & \\
\hline \multirow[t]{3}{*}{9} & \multirow[t]{3}{*}{ Legalitas Lahan } & \multirow[t]{3}{*}{$\begin{array}{l}\text { Kejelasan status } \\
\text { penggunaan } \\
\text { lahan }\end{array}$} & $\begin{array}{l}\text { Keseluruhan lokasi memiliki } \\
\text { kejelasan status penguasaan } \\
\text { lahan, baik milik sendiri atau } \\
\text { milik pihak lain }\end{array}$ & $(+)$ & & & & \\
\hline & & & $\begin{array}{l}\text { Sebagian lokasi memiliki } \\
\text { kejelasan status penguasaan } \\
\text { lahan, baik milik sendiri atau } \\
\text { milik pihak lain }\end{array}$ & $(-)$ & -1 & -1 & -1 & -1 \\
\hline & & & Sub Total & & -1 & -1 & -1 & -1 \\
\hline
\end{tabular}




\begin{tabular}{|c|c|c|c|c|c|c|c|c|c|c|c|}
\hline \multirow{3}{*}{ No } & \multicolumn{11}{|c|}{ Tabel 2. Tingkat Kekumuhan } \\
\hline & Kawasan & Jumlah nilai & \multicolumn{3}{|c|}{ Tingkat kebutuhan } & \multirow{2}{*}{$\begin{array}{l}\text { Jumlah nilai } \\
\text { aspek } \\
\text { pertimbangan } \\
\text { lain }\end{array}$} & \multicolumn{3}{|c|}{ Pertimbangan lain } & \multicolumn{2}{|c|}{ Legalitas lahan } \\
\hline & & $\begin{array}{l}\text { penilaian } \\
\text { kriteria dan } \\
\text { indicator } \\
\text { kekumuhan }\end{array}$ & $\begin{array}{c}\text { Kumuh } \\
\text { berat } \\
(71-95)\end{array}$ & $\begin{array}{c}\text { Kumuh } \\
\text { sedang } \\
(45-70)\end{array}$ & $\begin{array}{l}\text { Kumuh } \\
\text { ringan } \\
(19-44)\end{array}$ & & $\begin{array}{c}\text { Tinggi } \\
(11-15)\end{array}$ & $\begin{array}{l}\text { Sedang } \\
(6-10)\end{array}$ & $\begin{array}{l}\text { Rendah } \\
(1-5)\end{array}$ & $\begin{array}{l}\text { Legal } \\
(+)\end{array}$ & $\begin{array}{c}\text { Tidak } \\
\text { legal } \\
(-)\end{array}$ \\
\hline 1 & Sawunggaling & 65 & & $x$ & & 3 & & & $\mathrm{x}$ & & $\mathrm{x}$ \\
\hline 2 & Kenjeran & 77 & $x$ & & & 11 & $x$ & & & & $x$ \\
\hline 3 & Rungkut Kidul & 81 & $x$ & & & 11 & $x$ & & & & $x$ \\
\hline 4 & Wonokusumo & 57 & & $x$ & & 3 & & & $x$ & & $\mathrm{x}$ \\
\hline
\end{tabular}

Tabel 1 menjelaskan penilaian kekumuhan kawasan berdasarkan observasi fisik bangunan dan lingkungan beserta sarana dan prasarana yang tersedia. Selain itu untuk dijadikan sebuah pertimbangan dalam penilaian kekumuhan maka perlu observasi tentang nilai strategis dan kependudukan serta kondisi sosial, ekonomi dan budaya masyarakat setempat. Menurut Budiarjo dalam Wardhana \& Sulistyarso, (2015) permukiman kumuh adalah lingkungan hunian yang tidak layak huni, bercirikan ketidaksesuaian peruntukan lahan, kepadatan bangunan yang tinggi dengan luasan yang terbatas, rawan penyakit sosial dan penyakit lingkungan serta kualitas bangunan yang rendah dan membahayakan keberlangsungan kehidupan dan penghidupan. Berdasarkan penilaian tersebut, maka dapat terdapat klasifikasi, yaitu sebagai berikut :

a. Kelurahan Sawunggaling merupakan lokasi kumuh sedang dengan nilai 65 , dengan pertimbangan lain rendah dengan nilai 3 , dan status lahan ilegal.

b. Kelurahan Kenjeran merupakan lokasi kumuh tinggi dengan nilai, dengan pertimbangan lain tinggi, dan status lahan ilegal.

c. Kelurahan Rungkut Kidul merupakan lokasi kumuh tinggi, dengan pertimbangan lain tinggi, dan status lahan ilegal.

d. Kelurahan Wonokusumo merupakan lokasi kumuh tinggi, dengan pertimbangan lain rendah dengan nilai 3 , dan status lahan ilegal.

Tabel 2 menjelaskan tentang tingkat kekumuhan kawasan berdasarkan klasifikasi tingkat kebutuhan, pertimbangan lain dan legalitas lahan dengan hasil sebagai berikut :

a. Sawunggaling tingkat kekumuhan sedang.

b. Kenjeran tingkat kekumuhan berat

c. Rungkut Kidul tingkat kekumuhan berat

d. Wonokusumo tingkat kekumuhan sedang.

\section{Analisis Spasial}

Karakteristik wilayah kumuh harus dilihat secara spesifik, termasuk arah perkembangan, perubahan secara periodik dengan pendekatan beberapa indikator-indikator yang telah disepakati (7 indikator kumuh) sehingga mempermudah dalam menganalisa serta mengambil kebijakan. Deliniasi pertama permukiman kumuh sesuai dengan pengetahuan dan persepsi masyarakat tentang permukiman kumuh. Kemudian hasil survey lapangan disalin ke dalam peta atau dilakukan pemetaan mengidentifikasi deliniasi kumuh dan diamati secara visual.

Pemetaan wilayah kawasan kumuh dilakukan dengan metode SIG dengan cara deliniasi peta. Berikut karakteristik pada masing-masing kelurahan berdasarkan survey lapangan kemudian di digitasi menggunakan perangkat lunak SIG :

Kelurahan Sawunggaling

Persebaran permukiman kumuh Kelurahan Sawunggaling secara spasial, pada peta Gambar 2 berikut 


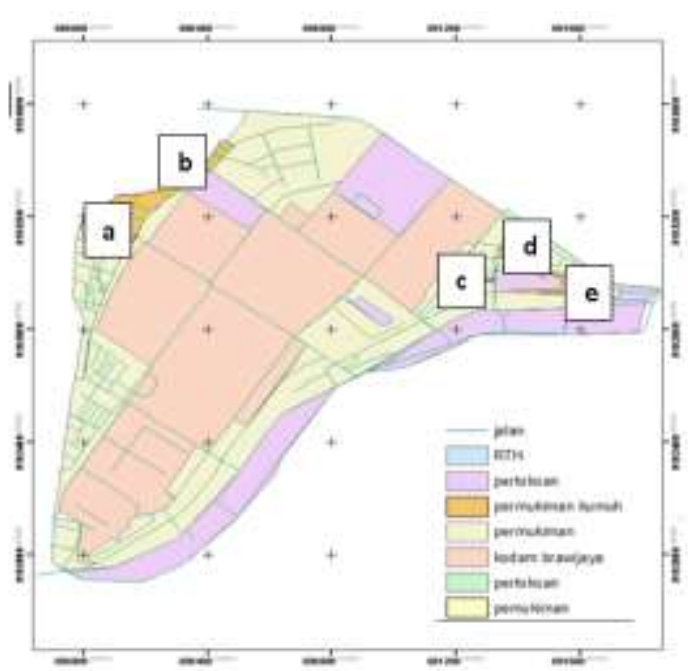

Gambar 2. Peta deliniasi sebaran permukiman kumuh Kel. Sawunggaling Karakteristik kawasan kumuh Kelurahan Sawunggaling termasuk di tingkat kekumuhan sedang berdasarkan salah satu aspek pertimbangan lain dengan nilai 1 untuk kriteria strategis lokasi yaitu lokasi kumuh tidak terletak pada fungsi strategis kabupaten/kota, kawasan tersebut tidak berada di pusat kota. Berikut karakteristik untuk kawasan kumuh Sawunggaling :

a. Bangunan non permanen tidak layak huni, dinding dari seng yang mudah roboh, dapat mengancam keselamatan jiwa dari penghuni bangunan tersebut

b. Jaringan listrik yang berada di RT 10 RW 6 ini telah tersebar dengan baik, kabel listriknya lebih tertata. Di setiap 7 meter sepanjang jalan, terpancang tiang listrik yang masih dalam kondisi cukup baik, kabel listriknya pun tertata rapi tidak ada yang tumpang tindih. Meski berada di gang - gang sempit, tiang listrik tersebut tidak mengganggu para pengguna jalan

c. Sistem pengangkutan sampah belum menyentuh unit, sarana dan prasarana sampah kurang memadai (TPSS, bak sampah, dan lain-lain)

d. Tingkat kepadatan bangunan tinggi sehingga rawan kebakaran, seperti gambar 3 berikut

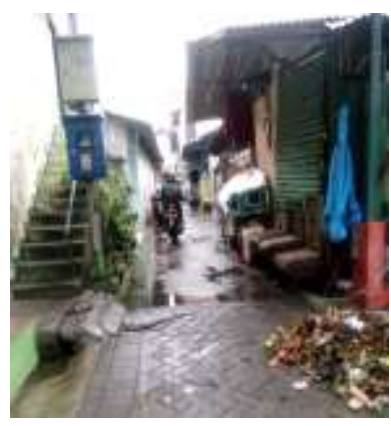

Gambar 3. Karakteristik Kawasan Kelurahan Sawunggaling

Kelurahan Kenjeran

Persebaran permukiman kumuh Kelurahan Kenjeran secara spasial, pada peta Gambar 4 berikut :

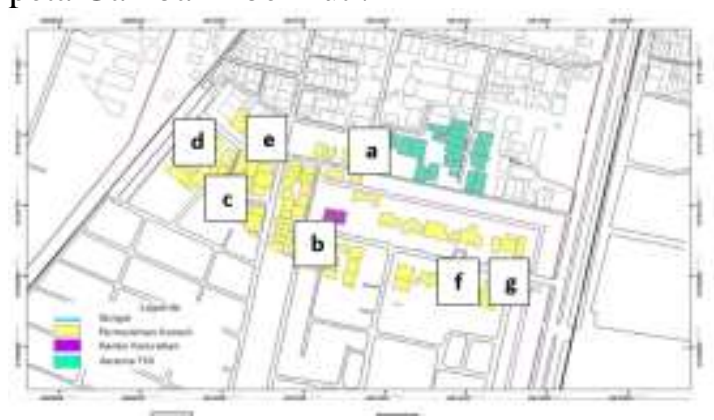

Gambar 4. Peta Deliniasi Sebaran

kawasan kumuh di Kel Kenjeran

Huruf a dan b terdapat jalan lingkungan yang tidak dilengkapi saluran drainase, berakibat jalan dan lingkungan permukiman sering tergenang. Jalan lingkungan perkerasan kualitas buruk ditunjukkan dengan huruf $\mathrm{c}$ dan d pada peta di atas.

Pada huruf e dan gambar 5 menunjukkan Bangunan rumah non permanen tidak layak huni, dinding terbuat dari papan triplek mudah terbakar.

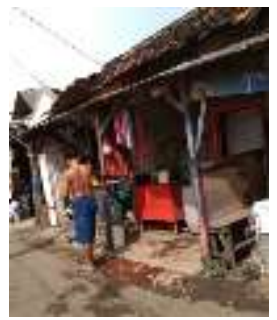

Gambar 5. Rumah non permanen

Pada peta untuk huruf $f$ berdasarkan survey terlihat bahwa Jalan lingkungan yang tidak dilengkapi saluran drainase. 


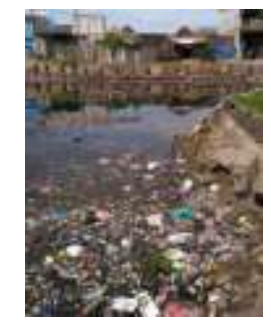

Gambar 6 Saluran Kelurahan Kenjeran

Saluran yang dipenuhi sampah tampak pada gambar 6 dikarenakan kurangnya kesadaran masyarakat, terlihat dari perilaku buang sampah ke sungai dan saluran.

\section{Kelurahan Rungkut Kidul}

Karakteristik permukiman kumuh di Rungkut Kidul secara spasial cenderung tidak teratur, seperti gambar 7 berikut :

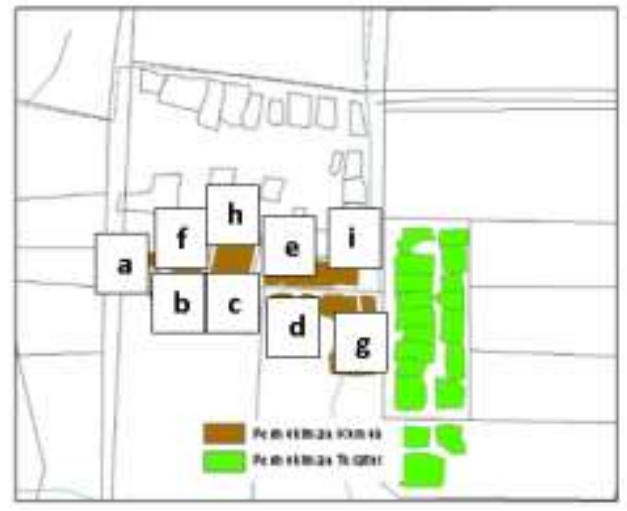

Gambar 7. Peta Deliniasi Sebaran kawasan kumuh di Kel Rungkut Kidul untuk :

Berdasarkan peta deliniasi di atas

Huruf a, b dan $\mathrm{c}$ jalan lingkungan perkerasan kualitas buruk, spot jalan lingkungan berupa tanah. Huruf d, kurangnya kesadaran masyarakat, perilaku membuang sampah ke sungai dan saluran. Point e, f dan g sistem pengangkutan sampah belum menyentuh unit, sarana dan prasarana sampah kurang memadai (TPSS, bak dan lainlain). Point $h$, pelayanan air bersih, tidak meratanya pelayanan PDAM pada akhirnya masyarakat membeli air dari pihak swasta seperti gambar 8 berikut :

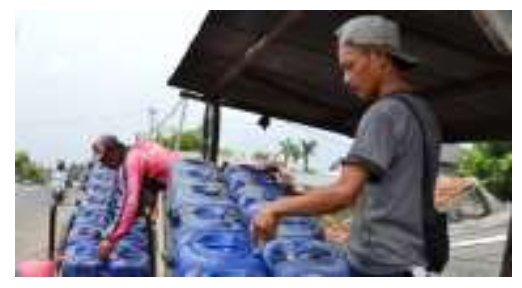

Gambar 8. Jual beli air selain PDAM

Point i, Lingkungan tidak dilengkapi sarana pemadam kebakaran dan kondisi jalan tidak dapat dilalui kendaraan pemadam kebakaran

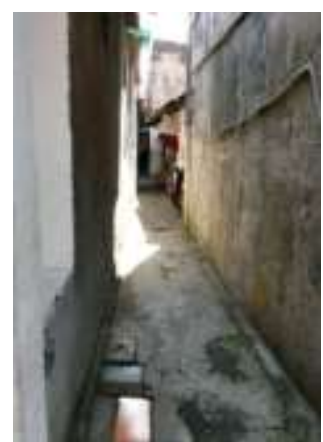

Gambar 9. Kondisi gang di perkampungan Kel. Kenjeran

Perkampungan di kawasan Kelurahan Kenjeran, diantara gang-gang sempit dan padat penduduk sehingga tidak dapat dilalui mobil pemadam kebakaran.

\section{Kelurahan Wonokusumo}

Karakteristik permukiman kumuh di Wonokusumo secara spasial cenderung berada di satu titik, seperti gambar berikut :

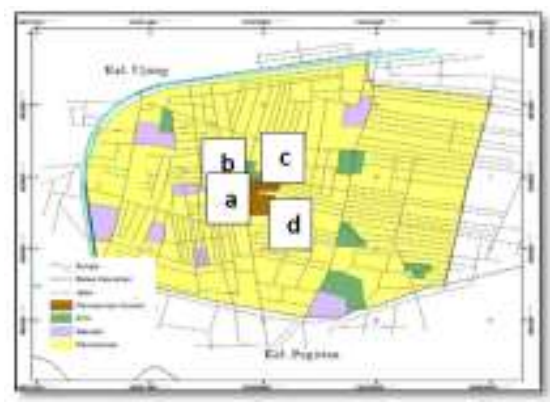

Gambar 10. Peta Deliniasi kawasan kumuh di Kel Wonokusumo

Titik a menunjukkan bangunan rumah non permanen tidak layak huni 


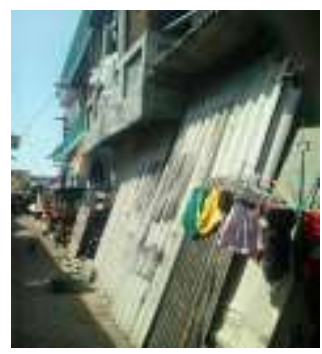

Gambar 11. Karakteristik permukiman kumuh Kelurahan Wonokusumo

Point b, Air buangan limbah rumah tangga masih menyatu dengan saluran drainase. Tidak adanya ruang terbuka publik dan minimnya RTH unit lingkungan. Pelayanan air bersih, tidak meratanya pelayanan PDAM.

Konsep penanganan di setiap masing-masing kelurahan dengan beberapa pertimbangan antara lain : kesiapan pemerintah, kesesuaian permasalahan dengan konsep penanganan, resiko dan keuntungan, resistensi masyarakat.

\section{KESIMPULAN}

Berdasarkan hasil penelitian yang telah dilakukan :

1. Tingkat kekumuhan permukiman kelurahan Sawunggaling dan Wonokusumo termasuk kategori sedang, kelurahan Kenjeran dan
Rungkut Kidul termasuk kategori berat.

2. Menetapkan kategori permukiman kumuh berdasarkan hasil penilaian yang dilakukan pada tahap sebelumnya Untuk memperoleh daftar kebutuhan penanganan dalam konteks pencegahan dan peningkatan kualitas permukiman kumuh baik itu pada skala kota/perkotaan maupun skala kawasan berdasarkan rumusan isu, potensi, permasalahan, dan hasil pemutakhiran profil permukiman kumuh pada tahapan sebelumnya.

3. Pemetaan secara spasial dibutuhkan dalam menentukan lokasi-lokasi permukiman kumuh perkotaan yang membutuhkan pencegahan dan penanganan.

\section{UCAPAN TERIMAKASIH}

Penulis mengucapkan terima kasih kepada Universitas PGRI Adi Buana yang telah memberikan dana hibah dosen pemula kepada penulis, serta kepada Pemerintah daerah setempat yang telah memberikan beberapa jenis data yang digunakan dalam penelitian ini.

\section{DAFTAR PUSTAKA}

Anoraga, J., Suryaningsih, M., Diinillah, A. S., Argentino, J., Hernowo, E., Eria, P., \& Yohana, L. (2014). Laporan Hasil Identifikasi Karakteristik Permukiman Kumuh di Kelurahan Ngagel Kecamatan Wonokromo Kota Surabaya. Surabaya. Retrieved from

https://www.academia.edu/8696640/HASIL_IDENTIFIKASI_KARAKTERISTIK_ PERMUKIMAN_KUMUH_DI_KELURAHAN_NGAGEL_KECAMATAN_WON OKROMO_KOTA_SURABAYA?auto=download

Jamaludin, A. N. (2015). Sosiologi Perkotaan "Memahami Masyarakat Kota dan Problematikanya” (Cetakan-). Bandung: CV Pustaka Setia.

Kurniati A \& Suhardi. (2012). Kajian Persebaran Permukiman Kumuh Di Surabaya Pusat Aryani Kurniati. Swara Bhumi, 2, 10-11. Retrieved from http://ejournal.unesa.ac.id/index.php/swara-bhumi/article/view/7700

Kuswartojo, T., Rosnarti, D., Effendi, V., K, R. E., \& Sidi, P. (2005). Perumahan dan Permukiman di Indonesia. Bandung: Institut Teknologi bandung.

Pekerjaan Umum dan Perumahan Rakyat No. 2. (2016). Peraturan Menteri No. 2. Pekerjaan Umum dan Perumahan Rakyat.

Wardhana, N. H., \& Sulistyarso, H. (2015). Faktor-Faktor Penyebab Kekumuhan Di Kelurahan Kapasari Kecamatan Genteng, Kota Surabaya. Jurnal Teknik ITS, 4(2), C-150-C-154.

Yuliani, S., \& D Rosyida, G. P. (2017). No Title. Wacana Publik, 1(2), 33-47. 
Anak Agung Sagung Alit W. \& Jelita Citrawati Jihan : Tingkat Kekumuhan dan Analisis Spasial Permukiman Kumuh Perkotaan (Studi Kasus : Surabaya Timur)

Zahro, F. (2017). Kawasan kumuh Surabaya Mencapai 150 Hektar, Dewan Sebut Indikator Hal - Hal Seperti ini. Surya.co.id, p. 1. Surabaya. Retrieved from http://surabaya.tribunnews.com/2017/08/18/kawasan-kumuh-surabaya-mencapai150-hektar-dewan-sebut-indikatornya-hal-hal-seperti-ini 